\title{
Application of principles of exercise training in sub-acute and chronic stroke survivors: a systematic review
}

Bernadette C Ammann ${ }^{1,2+}$, Ruud H Knols ${ }^{1+}$, Pierrette Baschung ${ }^{1,2,3 \dagger}$, Rob A de Bie ${ }^{2 \dagger}$ and Eling D de Bruin $2,4,5^{*+}$

\begin{abstract}
Background: There is increasing evidence for the beneficial effects of exercise training in stroke survivors. In order to reach the desired training effects, exercise training principles must be considered as this ensures the prescription of adequate exercises at an adequate dose. Moreover, exercise training interventions must be designed in a way that maximizes patients' adherence to the prescribed exercise regimen. The objectives of this systematic review were (1) to investigate whether training principles for physical exercise interventions are reported in RCTs for sub-acute and chronic stroke survivors, (2) to evaluate whether the RCTs reported the prescription of the FITT components of the exercise interventions as well as (3) patients' adherence to this prescription, and (4) to assess the risk of bias of the included studies.

Methods: We performed a systematic review of RCTs with exercise training as the primary intervention and muscular strength and/or endurance as primary outcomes. The Cochrane library's risk of bias (ROB) tool was used to judge the methodological quality of RCTs.

Results: Thirty-seven RCTs were included in this systematic review. Eighteen studies (48.7\%) focused on aerobic, $8(21.6 \%)$ on resistance and 11 (29.7\%) on combined interventions of aerobic and resistive strength exercise. Twenty-nine studies (78.4\%) included only chronic stroke survivors, 5 studies (13.5\%) only sub-acute stroke survivors whilst 3 studies (8.1\%) included both. In terms of principle of exercise training, $89 \%$ reported specificity, $75.7 \%$ progression, $48.7 \%$ overload, $37.8 \%$ initial values, $32.4 \%$ reversibility and $13.5 \%$ diminishing returns. One RCT described all principles of physical exercise training and 19 (51.4\%) all FITT components. Patients' adherence to exercise prescription was accounted for in 3 studies (8.1\%). Failure to report blinding in patients and participants and failure to report allocation concealment were the most prevalent methodological shortcomings.
\end{abstract}

Conclusions: Incomplete and inconsistent reporting of (1) training components, (2) underlying exercise training principles and (3) patient adherence together with (4) a broad variation in the methodological quality of the included RCTs limit both the utility and reproducibility of physical exercise programs in stroke patients.

Keywords: Stroke, Cerebrovascular accident, Aerobic exercise, Resistance exercise, Training principles, Training components

\footnotetext{
* Correspondence: eling.debruin@hest.ethz.ch

${ }^{\dagger}$ Equal contributors

Department of Epidemiology, CAPHRI School for Public Health and Primary

Care, Maastricht University, PO Box 616, 6200 MD Maastricht, the Netherlands

${ }^{4}$ Department of Health Sciences and Technology, Institute of Human

Movement Sciences and Sport, ETH Zurich, Wolfgang-Pauli-Str. 27, 8093

Zurich, Switzerland

Full list of author information is available at the end of the article
}

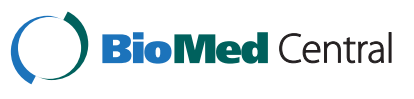

(c) 2014 Ammann et al.; licensee BioMed Central Ltd. This is an Open Access article distributed under the terms of the Creative Commons Attribution License (http://creativecommons.org/licenses/by/4.0), which permits unrestricted use, distribution, and reproduction in any medium, provided the original work is properly credited. The Creative Commons Public Domain Dedication waiver (http://creativecommons.org/publicdomain/zero/1.0/) applies to the data made available in this article unless otherwise stated. 


\section{Background}

Stroke is one of the leading causes of disability and death worldwide [1]. Due to demographic shifts in the global population, the number of affected people will increase, even with stable stroke incidence rates from approximately 1.1 million per year in 2000 to 1.5 million per year by 2025 [2,3]. The difference by 2025 will be \pm 150000 stroke events when compared with stable rates [3]. Approximately $50-70 \%$ of persons with stroke regain functional independence, but $15-30 \%$ of the stroke survivors are left with permanent disability [4]. Disability manifested by impairment of body function or body structure, activity limitation and/or participation restriction [5] - results in poor physical fitness, defined as "the ability to carry out daily tasks with vigor and alertness, without undue fatigue, and with ample energy to enjoy leisure-time pursuits and respond to emergencies" [6].

Physical fitness includes health-related (cardiorespiratory endurance, muscular endurance, muscular strength, flexibility and body composition) and skill-related components (agility, coordination, balance, speed, reaction time and power) [6]. All of these render the development of exercise training programs for stroke rehabilitation a complex enterprise. Although several exercise recommendations have been published [7-9], the complex interactions present in stroke rehabilitation preclude the definition of specific, detailed exercise prescriptions. Still, several systematic reviews and meta-analyses provide evidence that aerobic exercise and resistive strength training are beneficial to improve aerobic capacity, walking distance, muscular strength and physical function in stroke survivors without increasing pain or tone in the paretic limbs [10-17]. Thus, the available literature suggests that impaired physical fitness is partly responsible for the disability evident in stroke survivors.

When reporting the results of an exercise intervention, it is important that the precise principles of the exercise training are consistently and accurately reported $[18,19]$. Recognised principles are specificity, overload, progression, initial values, reversibility and diminishing returns (Table 1) [18-20]. Their application in the design of an exercise intervention ensures that the dose and type of exercise is planned such that benefits for the recipient are maximized. Furthermore, it seems fair to assume that when principles of exercise training are applied to the development of exercise protocols, clinicians in practical settings can have greater confidence that non-significant research findings reflect deficiencies in exercise efficacy rather than deficiencies in exercise prescription [18].

However, a perfectly planned intervention adopting all the principles of exercise training is almost useless when it is not reported in sufficient detail to permit intervention replication and results interpretation. Therefore, the
Table 1 Exercise training principles

\begin{tabular}{|c|c|}
\hline Principle & Description \\
\hline Specificity & $\begin{array}{l}\text { Exercising a certain body part or component of the } \\
\text { body primarily develops that part: To become better } \\
\text { at a particular exercise or skill, you must perform that } \\
\text { exercise or skill. }\end{array}$ \\
\hline Overload & $\begin{array}{l}\text { A greater than normal stress or load on the body is } \\
\text { required for training adaptation to take place. The } \\
\text { body will adapt to this stimulus. }\end{array}$ \\
\hline Progression & $\begin{array}{l}\text { A gradual and systematic increase of the workload } \\
\text { over a period of time will result in improvements in } \\
\text { fitness without risk of injury. }\end{array}$ \\
\hline Initial values & $\begin{array}{l}\text { Improvement in the outcome of interest will be } \\
\text { greatest in those with lower initial values. In other } \\
\text { words, those with lowest level of fitness have greatest } \\
\text { room for improvement. }\end{array}$ \\
\hline Reversibility & $\begin{array}{l}\text { Once a training stimulus is removed, fitness levels will } \\
\text { eventually return to baseline ('use it or lose it!'). }\end{array}$ \\
\hline $\begin{array}{l}\text { Diminishing } \\
\text { returns }\end{array}$ & $\begin{array}{l}\text { Refers to the decreasing expected degree of } \\
\text { improvement in fitness as individuals become fit, } \\
\text { thereby increasing the effort required for further } \\
\text { improvements. }\end{array}$ \\
\hline
\end{tabular}

prescription of the components of the exercise program and participants' adherence to that exercise prescription should ideally be reported according to the so-called FITT components (Frequency, Intensity, Time and Type of exercise) (Table 2) [21]. FITT represents components of physical conditioning programs that determine effect on cardiorespiratory endurance, muscular strength and/or endurance and flexibility. Furthermore, participants' adherence to each of the prescribed FITT components should be reported. Detailed reporting of the dose of exercise prescribed (and received) allows for an adequate interpretation of results - including possible dose-response effects - and provides information about the tolerability and safety of the intervention. Without detailed information on both the type and dose of exercise that is prescribed and actually received, developing optimally designed and dosed exercise prescriptions for a desired level of benefit (i.e., response) remains difficult, thus limiting the implementation of evidence-based training programs.

Well-designed randomized controlled trials (RCTs) provide the best evidence regarding the effectiveness of health care interventions. Trials with inadequate methodological approaches may overstate treatment effects and bias results. Critical appraisal of the quality of clinical trials is possible only if the design, execution and analysis of RCTs are described thoroughly and accurately $[22,23]$. Thus, in order to properly interpret the results of an RCT, it is important to know the principles underlying the prescribed exercises, the FITT components of the intervention, the adherence to these components and the methodological quality of a trial.

The objectives of this systematic review were (1) to investigate whether training principles for physical exercise 
Table 2 FITT components applied to physical conditioning programs

\begin{tabular}{llll}
\hline Frequency & Intensity & Time & Type \\
\hline The number of times an exercise or & Refers to how much work is being & The length or duration in & E.g. running/swimming for cardio \\
activity is performed generally & $\begin{array}{l}\text { performed or the magnitude of the } \\
\text { expressed in sessions, episodes or } \\
\text { effort required performing an activity } \\
\text { bouts per week. }\end{array}$ & $\begin{array}{l}\text { or exercise. } \\
\text { performed, usually expressed } \\
\text { in minutes. }\end{array}$ & $\begin{array}{l}\text { resistance machines for muscular } \\
\text { strength or endurance. }\end{array}$ \\
\hline
\end{tabular}

interventions are reported in RCTs for sub-acute and chronic stroke survivors, (2) to evaluate whether the RCTs reported the prescription of the FITT components of the exercise interventions as well as (3) patients' adherence to this prescription, and (4) to assess the risk of bias of the included studies.

\section{Methods}

\section{Search strategy}

An electronic search strategy was developed and performed by a librarian of Zurich University, using the databases Medline, OvidSP, EMBASE, CINAHL, PsycInfo and the Cochrane Library (Figure 1). The search was restricted to English language literature from inception of the databases up to February 2014. Combinations of the following medical subject headings $(\mathrm{MeSH})$ and free text words were used: stroke (cerebral stroke, vascular accident, brain vascular accident, apoplexy, cerebrovascular apoplexy, cerebrovascular stroke, cerebrovascular accident) and exercise (cardiovascular training, cardiopulmonary training, cardiorespiratory training, aerobic training, endurance training, exercise, endurance exercise, ergometry, resistive strength training, physical exercise principles, specificity, overload, progression, initial values, reversibility, diminishing returns).

\section{Eligibility criteria}

Studies were eligible for inclusion if they: (1) were RCTs (2) evaluated the effects of aerobic physical exercise training or resistive strength training alone or in combination, (3) included adult (> 18 years) sub-acute or chronic stroke survivors, and (4) included aerobic capacity and/or aerobic endurance and/or muscle strength as primary outcome measurement. The sub-acute phase

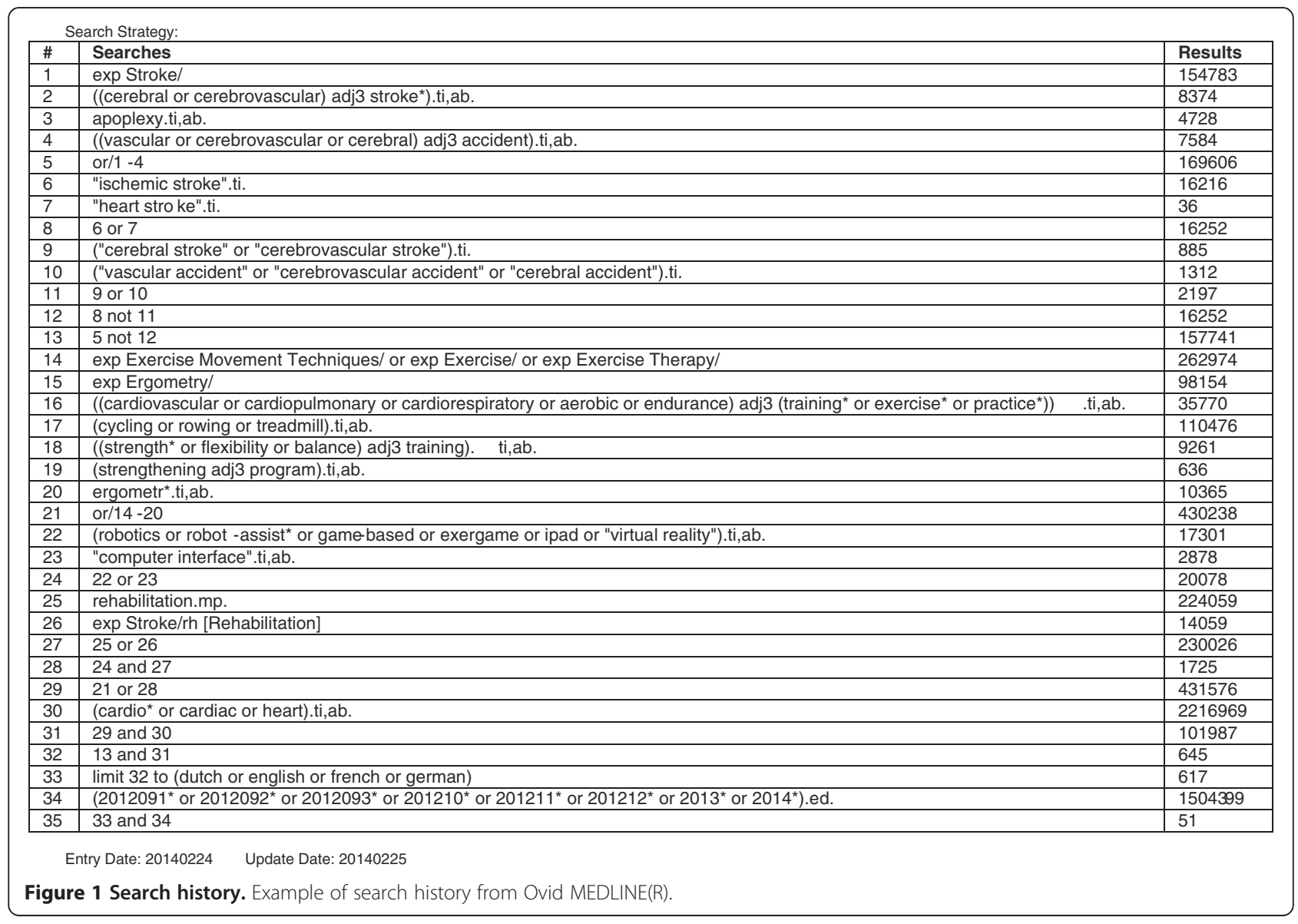


was defined as the range between 15 and 180 days after initial stroke, thus all RCTs with a mean or median within this time range were considered a sub-acute population. Chronic stroke was defined as the openended time period starting 180 days after initial stroke and characterised by generally slow or no clinical progress [24].

\section{Study selection}

After removal of duplicates, the search results were screened for eligibility by two teams of two reviewers (BA/PB and RK/EDB), sharing the retrieved citations. In case of disagreement within one team, a reviewer from the other team served as referee.

\section{Data collection process}

Using existing systematic reviews that evaluated the effects of exercise interventions in cancer patients [18,19], BA created a purpose-designed data collection sheet to include information about each included RCT regarding (1) the reporting of exercise training principles, (2) the description of the exercise training components, (3) participants' adherence to the training plan according the FITT components, and (4) further quality characteristics of the included studies (risk of bias (ROB)). Corresponding authors of selected trials were contacted by email to retrieve unpublished data. Three reviewers (BA, PB and RK) independently collected and rated these data.

\section{Rating of the reporting of exercise training principles}

For each exercise principle, three rating categories were used: reported $(+)$, not reported $(-)$ and unclear or inconsistently reported (?).

Rating of the description of exercise training components and participants' adherence to the training plan

Corresponding to the rating of the training principles, we judged the description with $(+)$ if the component of the exercise prescription was reported; $(-)$ if the component was not reported and (?) if it was unclearly or inconsistently reported. Participants' adherence to the exercise prescription was judged with $(+)$ if the adherence of each component to the exercise prescription was reported; (-) if the adherence was not reported and (?) if it was unclearly or inconsistently reported.

\section{Rating of risk of bias in individual studies}

Two reviewers (BA and $\mathrm{PB}$ ) independently applied the Cochrane Collaboration's tool for assessing ROB to assess the risk of over- or under-estimating the effects of an intervention [25]. The five bias domains (selection, performance, detection, attrition and reporting bias) were judged as: low ROB (+), unclear ROB (?) or high ROB (-). Rating (+) is unlikely to alter the results seriously, (?) raises some doubt about the results and (-) seriously weakens confidence in the results. With unclear information on an item, the score given was (?). The arbitration of a third reviewer (RK) was used in the event of any disagreement between the rating reviewers (BA and $\mathrm{PB}$ ).

\section{Data synthesis}

All extracted data from the RCTs were transformed into percentages. The percentage agreement and Cohen's kappa were calculated and interpreted in accordance with Landis and Koch's benchmarks for assessing the agreement between raters: poor $(\leq 0)$, slight (between 0.0 and 0.20 ), fair (between 0.21 and 0.40), moderate (between 0.41 and 0.60), substantial (between 0.61 and 0.80 ), and almost perfect (between 0.81 and 1) [26]. The PRISMA statement was followed for reporting items of this systematic review $[27,28]$.

\section{Results}

\section{Study selection}

The systematic search provided a total of 1599 citations. After automatic de-duplication, 1265 hits remained. From this total, 1158 titles and abstracts failed to meet the inclusion criteria and were thus excluded. The remaining 107 abstracts were retrieved as full texts and screened together with their references. Sixteen additional studies were considered after manually scanning the reference lists of identified studies. After excluding another 86 studies based on in- and exclusion criteria, 37 studies were included in the final review (Figure 2).

\section{Study characteristics}

From the 37 studies with a grand total of 2135 participants, 18 studies $(48.7 \%)$ focused on aerobic exercises [29-46], 8 (21.6\%) on resistance exercises [47-54] and 11 (29.7\%) on combined interventions of aerobic and resistive strength exercise [55-65] (Additional file 1). Most of the included studies compared an experimental exercise intervention to usual care, or to an alternative intervention. Four RCTs included 3 or 4 training groups in their design $[38,53,58,59]$. Twenty-nine studies $(78.4 \%)$ included chronic stroke survivors [32-41,43,44,46-54,58-65], 5 (13.5\%) included sub-acute stroke survivors [29-31,55,56] whilst 3 studies $(8.1 \%)$ included both types of patients [42,45,57]. In the 18 studies evaluating aerobic exercise only $(n=1278)$ [29-46], treadmill training with or without body weight support was the most frequently used exercise intervention. In the 8 studies that focused on resistance training $(n=235)$ [47-54], circuit classes with progressive strength training constituted the most frequently used intervention. Of the 11 studies focusing on combined interventions of aerobic and resistive strength exercise $(n=622)$ [55-65], most focused on improvement of the lower extremity or both 


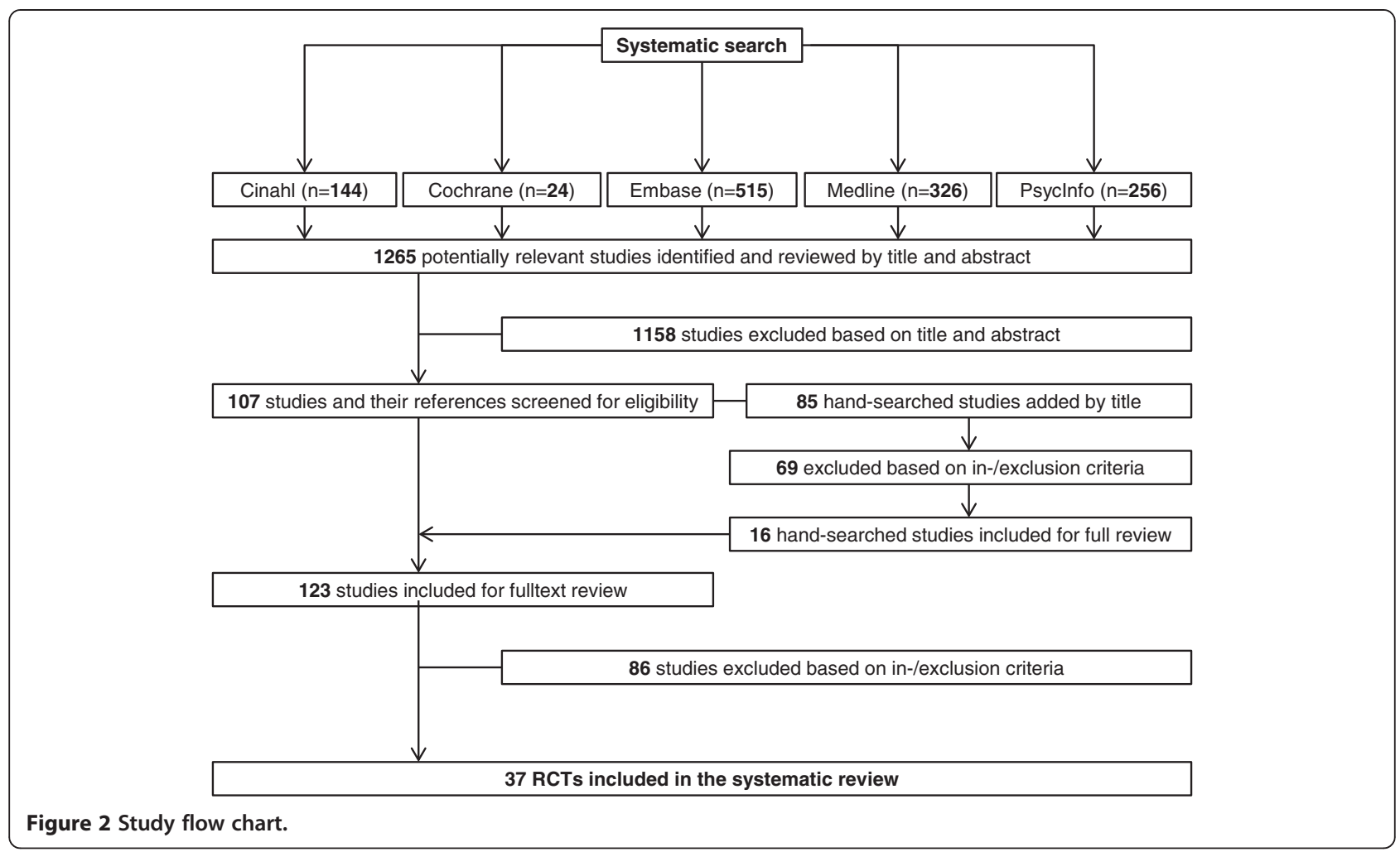

upper and lower extremities. No study focused on improvement of the upper extremity in the intervention group. The length of the exercise interventions ranged from 3 weeks [38] to 12 months $[42,45]$. Sixteen studies $(43.2 \%)$ described follow-up measurements [29-34,36-38,41,47,51,54,58,61,62] in which the follow-up period ranged from 2 months [51] to one year $[32,62]$.

\section{Application of exercise principles}

One study described all six principles of exercise training [32], one described 5 out of 6 [47], 11 described 4 out \# of 6 [34,36,37,40,41,43,44,46,53,58,60] and 12 described three training principles [30,35,38,39,49,51,59,61-64] (Additional file 2: Table S1a-c). The remaining 12 studies, representing $32.4 \%$ of the included studies, described just one $[42,48,50,57]$ or two $[29,31,33,45,52,54-56,65]$ of these. With respect to the specific training principles, $33(89.2 \%)$ of the RCTs reported specificity [30,32,34-56, 58-65], 28 (75.7\%) described progression [32-41,43,44,46, 47,49,51-53,55,56,58-65], 18 (48.7\%) described overload [32,34-37,39,40,43,44,46,47,49,53,58-60,63,64], 14 (37.8\%) described initial values [29-32,40,41,43-47,53,57,60], 12 (32.4\%) described reversibility [29,31-34,38,41,47,51,54, $61,62]$ and 5 (13.5\%) described diminishing returns [30,32,36,37,58]. Nineteen studies (51.4\%) did not describe the initial values of their participants [34-37,39,42,48-51, 55,56,58,59,61-65] and 14 (37.8\%) did not describe the principle of overload [29-31,33,42,48,50,51,54-56,61,65].
Seven studies (18.9\%) were unclear in describing progression [29-31,42,45,48,57], whilst $5(13.5 \%)$ were unclear with respect to overload $[38,41,52,57,62]$.

\section{Prescription of the exercise training}

The reporting of each FITT component of the exercise prescription is summarized in Figure 3. Details of the FITT component reporting of each study are presented in the Additional file 1. In general, Frequency was described in 35 studies (94.6\%) [29-32,34-41,43-65], leaving 2 studies (5.4\%) that were unclear in their reporting $[33,42]$. Twenty-two studies $(59.5 \%)$ reported training Intensity [32-37,39-41,43-47,49,50,53,58,59,61,64,65], 6 studies $(16.2 \%)$ did not report this item [42,51,54-57] whilst 9 studies (24.3\%) reported it unclearly [29-31,38, $48,52,60,62,63]$. Thirty-four studies (91.9\%) reported the component Time [29-32,34-48,50-52,54-65] and 35 RCTs (94.6\%) reported Type [29-32,34-56,58-65] of physical exercise. Two studies (5.4\%) did not report the Time dedicated to exercises $[33,49]$ whilst two studies (5.4\%) unclearly reported the Type of each exercise bout [33,57]. Nineteen studies (51.4\%) described all FITT components [32,34-37,39-41,43-47,50,58,59, 61,64,65], 15 (40.5\%) reported 3 of 4 FITT components [29-31,38,48,49,51-56,60,62,63], two (5.4\%) reported 2 out of 4 items $[42,57]$, and one $(2.7 \%)$ reported one of the 4 items [33]. 


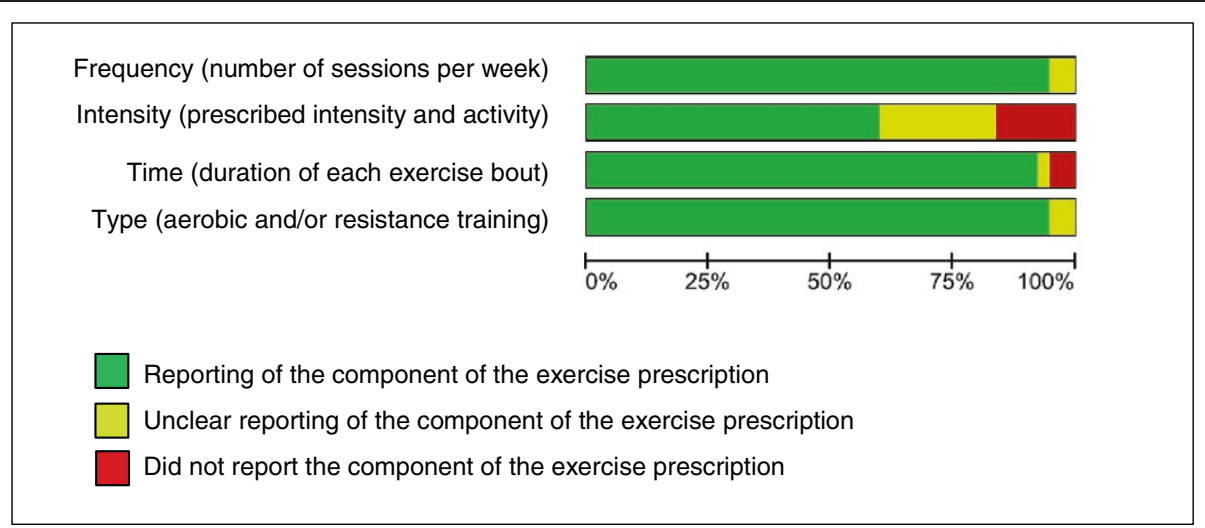

Figure 3 Reporting of the FITT components. Review authors' judgments about the prescription of the training program according to the FITT components presented as percentages across all included studies.

\section{Adherence to the exercise training}

Adherence to each FITT component of the exercise prescription is summarized in Figure 4. Twenty-one studies (56.8\%) reported the item Frequency [30,32,36,37,40-42, $46-52,54-57,61,63,65], 5$ studies $(13.5 \%)$ reported the item Intensity of the activity [32,37,46,55,58], 7 studies (18.9\%) reported the item Time duration of each exercise bout $[32,37,40-42,55,56]$ and 9 studies $(24.3 \%)$ reported the item Type of exercise [32,37,40,41,46,50,52,55,61]. Three studies $(8.1 \%)$ unclearly reported adherence to the Type of exercise $[48,54,63]$ whilst 3 studies (each representing 2.7\%) unclearly reported the items Frequency [60], Intensity [63] and Time [46] of the intervention. Fifteen (40.5\%) studies did not report the item Frequency $[29,31,33-35,38,39,43-45,53,58,59,62,64], 29$ studies did not report the item Time (78.4\%) [29-31,33-36,38,39, 43-45,47-54,57-65], 25 studies did not report the Type of exercises completed (67.6\%) [29-31,33-36,38,39,42-45, $47,49,51,53,56-60,62,64,65]$ and the item Intensity was not reported in 31 studies (83.8\%) [29-31,33-36,38-45, 47-54,56,57,59-62,64,65]. Fifteen studies $(40.5 \%)$ did not report any of the FITT components [29,31,33-35,38, $39,43-45,53,59,60,62,64], 11$ studies $(29.7 \%)$ reported 1 out of 4 components $[30,36,47-49,51,54,57,58,63,65]$ and 5 studies (13.5\%) reported 2 out of 4 items [42,50, 52,56,61]. Three studies (8.1\%) reported all four FITT items $[32,37,55]$.

\section{Methodological risk of bias}

Methodological quality varied substantially across the studies (Additional file 3: Table S2a-c). All included studies had a low risk of selective reporting (reporting bias) [29-65], 19 (51.4\%) had a low risk concerning the blinding of their outcome assessments (detection bias) [29,31,32,34-36,40,42,45,46,48-50,52,55,57,60,61,63], 21 studies $(56.8 \%)$ had a low risk of incomplete outcome data (attrition bias) [32,34,35,40-42,46-50,52,54-57,59, 61-63,65], 19 studies (51.4\%) had a low risk of selection bias concerning allocation concealment [32,33,35,38, $40-46,48,50,51,56,57,61-63]$ and 22 studies (59.5\%) showed a low risk of selection bias regarding random sequence generation [32,33,35-38,40-42,45,46,48,51,55-63].

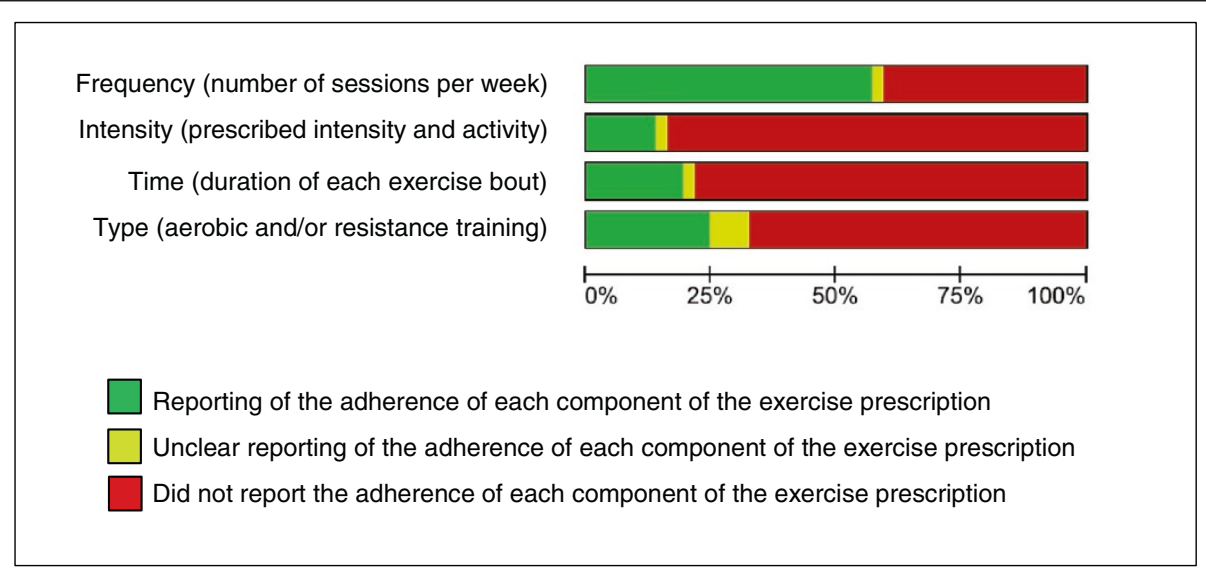

Figure 4 Adherence to the FITT components. Review authors' judgments about the adherence of the study sample to the exercise prescription according to the FITT components presented as percentages across all included studies. 
With the exception of one study [40], the blinding of participants and personnel (performance bias) was a weak point in all studies: 30 studies $(81.1 \%)$ had an unclear risk [29-39,43,44,46,48-60,62,64,65] whilst the remaining 6 studies (16.2\%) had a high risk of performance bias $[41,42,45,47,61,63]$.

The inter-rater agreement of the 3 rating categories "low, unclear, high ROB" of the quality assessment was substantial (Kappa: 0.71, SE of kappa: 0.04, 95\%CI: 0.630-0.796). The number of observed agreements between the two raters was $83.3 \%$ of the judgments.

\section{Discussion}

This systematic review evaluated the explicit reporting of the principles of (aerobic and/or resistance) exercise training in sub-acute and chronic stroke survivors. The results showed that these principles were inconsistently reported. This result impacts on the clinical reproducibility of trials, as clinicians cannot be confident whether non-significant findings are due to lack of efficacy or occur through limitations in treatment prescription. The risk of bias in the 37 studies depended on the bias domain being judged.

In this review, specificity and progression were the most frequently applied (i.e., explicitly reported) training principles, in $89.2 \%$ and $75.7 \%$ of reviewed studies respectively. Accordingly, most exercise trials clearly outlined training progression and designed their intervention to be specific to the target population, thus warranting reproducibility with respect to these training principles. In contrast, initial values and overload principles were not described in $37.8 \%$ and $48.7 \%$ of the reviewed RCTs respectively. Without knowing the baseline fitness levels of studied participants, it is difficult to generalize the findings to a clinical setting. Moreover, it is impossible to verify whether the provided exercise program was of adequate intensity, which hinders the interpretation of results. This situation is further aggravated by the fact that only $59.5 \%$ of the included studies reported the Intensity of their exercise training. Unfortunately, it is not always feasible to accurately measure the intensity of an exercise due to lack of equipment to monitor energy, work and/or power. In addition, a lack of knowledge of the exact effort (in terms of energy, work and/ or power) that healthy subjects require to perform certain exercises [66] further complicates the dosing of exercises in patient populations. Only in studies where the mechanical output of physical activity can be controlled, such as by using cycle ergometry [35,39] or leg press machines [49], is the required effort known. Yet even in light of these difficulties, it should always be possible to report the number of repetitions required in a certain exercise or the total time dedicated to exercise training. The latter was successfully described in
91.9\% of the exercise trials included in this review. Furthermore, energy spent performing certain exercises might be assessed via proxy measures such as the Borg's Rating of Perceived Exertion and Pain Scales [67]. Although perceived exertion is a subjective measure, it may nonetheless provide a fairly good estimate of the actual heart rate during physical activity and hence the intensity of that activity. Indeed, practitioners generally agree that perceived exertion ratings of 12 to 14 on the Borg Scale suggest a moderate level of intensity of physical activity [67].

There is evidence of a positive relationship between the time dedicated for therapy and therapy outcomes, indicating a positive relationship between dose and response [68,69]. Lohse and colleagues [68] and Kwakkel et al. [69] both reported that the benefit of large increases in therapy volume is similar across a range of post-stroke times. That is, patients will benefit from an increase in therapy volume, regardless of whether their stroke occurred several months or several years ago. This finding also highlights the importance of exercise even after discharge from rehabilitation and reflects the training principle of reversibility: i.e. 'use it or lose it'. Following the principle of diminishing returns - reported in only $13.5 \%$ of the studies - the effort required to achieve further improvements should increase over time. In line with the findings of the present systematic review, the principles of diminishing returns and reversibility were the least reported exercise principles in RCTs on physical training interventions in cancer survivors according to two recently published systematic reviews $[18,19]$. A possible explanation is related to the fact that the assessment of these training principles requires follow-up measurements, which would increase research expenses and heighten the burden on patients participating in the study. However, assessment and reporting of both principles are crucial to determine the volume, frequency and intensity required in an exercise intervention to achieve durable long-term benefits for stroke patients [20].

Perhaps the most striking finding in this review was the discrepancy between the reporting of the FITT components in the exercise intervention (Figure 3) and the adherence to those components (Figure 4). To illustrate: 94.6\% of the studies reported the FITT component Type yet only $24.3 \%$ of the studies reported adherence to this component. Similarly, Time, Frequency and Intensity was reported by $91.9 \%, 94.6 \%$ and $59.5 \%$ of the studies, respectively (Figure 3), yet adherence to these components was reported in only $18.9 \%, 56.8 \%$ and $13.5 \%$ of them (Figure 4). This general failure of reporting adherence with respect to the FITT components all but obscures this crucial aspect of an intervention [21] and hence prohibits important considerations that must be made 
before replicating an intervention in a clinical setting. There are several reasons why exercise programs might not be performed as prescribed, including patientrelated factors (e.g. fatigue or depression [70,71]; lack of motivation; stroke impairments [72,73]), environmental factors (e.g. lack of transportation) or health concerns (e.g. fear of falls [74]). For clinicians and researchers alike, addressing these perceived barriers to exercise training is crucial both for successful rehabilitation and for provision of replicable exercise training programs. Promising first steps in breaking down these perceived barriers to training might be to remove costs for transportation or to integrate patients' relatives in the rehabilitation process [75]. In support of the latter, it has been found that social support is an important motivator in achieving and maintaining physical fitness [72].

The most prevalent methodological shortcoming of the included studies was the absence of blinding of participants and personnel in $97.3 \%$ of the included RCTs. This is in line with findings of other systematic reviews of stroke exercise training $[10,16]$. Such lack of blinding can cause overestimations of the treatment effect and therefore bias the study results. For example in a metaepidemiological study by Wood et al. [76], estimates of treatment effects were exaggerated by $7 \%$ in non-blinded compared to blinded trials. Although blinding of participants and personnel may not always be feasible, it may still be possible to blind the outcome assessments. In this review, 19 RCTs (51.4\%) had a low risk concerning this form of blinding (detection bias). Objectively assessed outcomes are less susceptible to bias than subjectively assessed ones [76]. Therefore, efforts to minimize other forms of bias are particularly important when objective measurements are not feasible. Allocation concealment was ambiguous in $48.6 \%$ of studies whilst 15 studies (40.5\%) had a high or unclear risk of selection bias regarding random sequence generation. These findings are in line with those of other reviews [77]. Because concealment of allocation can lead to exaggeration of treatment effects [78], details of both sequence generation and concealment of allocation should always be clearly reported [22,23].

Through improving cardiovascular fitness and muscle strength, disability after stroke may be reduced [16]. This is an important aspect of training since regaining function and independence are important goals for patients. The benefits of aerobic exercise might even be broader: Converging evidence suggests that aerobic exercise is a valuable intervention for improving brain function $[79,80]$ and promoting neuroplasticity by upregulation of neurotrophins [81]. Aerobic exercise programs after stroke have also been shown to improve blood pressure [82] and arterial function [83], as well as enhancing glucose regulation [84]. It is also highly plausible that exercise could be an effective treatment for fatigue [85], especially in combination with the treatment of the associated depressive symptoms of poststroke fatigue (PSF) [86], even though it must be noted that there is insufficient evidence of an association between PSF and physical fitness to date [70]. Taken together, the total body of evidence clearly highlights the importance of maintaining physical fitness after stroke, as it greatly reduces the effort required to carry out daily tasks and therefore contributes to a more active and independent lifestyle [87]. Moreover, an optimal level of physical fitness decreases the risk of subsequent stroke, which is particularly significant in view of the fact that around 30\% of stroke survivors will have recurrent stroke within their lifetimes, of which $18 \%$ will prove fatal [75]. Given the great restorative potential of achieving and maintaining physical fitness after stroke, the need for RCTs to properly report both exercise prescription and adherence to exercise prescription - which would allow full replication of positive findings in clinical settings - becomes particularly pressing.

\section{Call for transparency to facilitate evidence-based practice}

In contemporary clinical practice, clinicians must ensure that the time allotted for therapy is used effectively and efficiently. To be successful, it is imperative that the goals of an exercise program be both reasonable and attainable $[20,88]$. These aims are best achieved with a custom-made and individually tailored training program with variables that can be manipulated from workout to workout [21]. Such variables might be the choice, volume, intensity and order of exercise as well as the frequency and length of training and the length of rest periods. In order to achieve an optimum training effect, programs used in research should comply with and clearly report the exercise training principles [20] and FITT components [21]. This is expected to facilitate application of effective programs in clinical practice. However, the current state of the evidence still renders it difficult for practitioners to choose the optimal evidence-based training program for their individual patients. Only by reporting sufficient detail about volume and type of exercise actually performed by trial participants will more accurate interpretations of study outcomes and more appropriate translations of programs into non-research settings be permitted. A good starting point for future trials would be the American Heart Association (AHA) recommendation for stroke exercise training [89] (modified by Billinger et al. [75]). Such a detailed description of adherence, in combination with an equally detailed description of the developed program and the target population, would greatly facilitate reproduction of trials in clinical settings. 


\section{Limitations of the review}

To the best of our knowledge, this systematic review is the first to investigate the application of exercise training principles for sub-acute and chronic stroke patients. The review focuses on the reporting of intervention content rather than on the actual intervention outcomes. In striving to achieve a robust systematic review, we developed and documented the methods (e.g. a systematic search strategy and several worksheets for collecting and synthesizing the data) in advance. Due to the large number of existing trials on stroke rehabilitation, we decided to focus exclusively on RCTs to ensure high external validity. Nevertheless, some limitations remain. Firstly, we limited our search to English language peer-reviewed journal literature. Hence clearly there is a possibility that important RCTs published in other languages were missed. Secondly, due to the scope of the review, we did not perform meta-analyses of RCT results and hence cannot make recommendations concerning preferable exercise interventions for sub-acute and chronic stroke survivors. For training recommendations based on best available evidence we refer to the literature [75,89]. Thirdly, although we included only RCTs in this review, the clinical and methodological diversity of the studies considered was still rather large. Finally, we exclusively focused on sub-acute and chronic stroke patients; thus our results cannot be generalized to acute patient groups. The reason for not including this patient population is twofold: First, there is no consensus in the literature as to how early physical activity should begin after a stroke [90] and second, information on how to influence and evaluate aerobic capacity in severely affected individuals is lacking [10].

\section{Conclusions}

The present systematic review showed that RCTs on aerobic and/or resistance rehabilitation training in subacute and chronic stroke survivors incompletely and inconsistently reported the prescription of, and especially the adherence to, exercise prescriptions in investigated training programs. Allowing practitioners to use established training principles to guide the therapy process will help them to plan and implement their stroke therapy more efficiently and more effectively. Therefore it is of the utmost importance for researchers to plan and document investigated exercise interventions in as detailed a manner as possible. The consideration of all principles of exercise training and all FITT components in the development and reporting of exercise prescriptions is a course of action ideally fitted to this purpose.

\section{Additional files}

Additional file 1: Characteristics of included RCTs.
Additional file 2: Table S10. Application of Principles of Exercise Training. a: Aerobic exercise only $(n=18)$. b: Resistance exercise only $(n=8)$. c: Aerobic and resistance exercises $(n=11)$.

Additional file 3: Table S2. Rating of risk of bias in individual studies. a: Aerobic exercise only $(n=18)$. b: Resistance exercise only $(n=8)$. c: Aerobic and resistance exercises $(n=11)$.

Competing interests

The authors declare that they have no competing interests.

\section{Authors' contributions}

BA conceived the methodology and carried out data collection, quality assessment, data analysis and manuscript writing. RK supervised progress, participating in methodology conception as well as quality assessment, data analysis and manuscript writing \& revision. PB helped with data collection, quality assessment and data analysis. RDB contributed in manuscript writing. EDB initiated the study, supervised progress, helped with methodology conception, data collection and manuscript writing \& revision. All authors read and approved the final manuscript.

\section{Acknowledgements}

The authors thank Martina Gosteli for performing the search strategy. Further thanks go to Dr R van de Langenberg and to Dr Martin J Watson for proof reading the manuscript on English and structure. This work was partially supported by the REWIRE project (http://www.rewire-project.eu), funded by the European Commission under the FP7 framework with contract 287713.

\section{Author details}

${ }^{1}$ Directorate of Research and Education, Physiotherapy \& Occupational Therapy Research, University Hospital Zurich, Gloriastrasse 25, 8091 Zurich, Switzerland. ${ }^{2}$ Department of Epidemiology, CAPHRI School for Public Health and Primary Care, Maastricht University, PO Box 616, 6200 MD Maastricht, the Netherlands. ${ }^{3}$ Department of Health, Institute of Physiotherapy, Zurich University of Applied Sciences, Technikumstrasse 9, 8401 Winterthur, Switzerland. ${ }^{4}$ Department of Health Sciences and Technology, Institute of Human Movement Sciences and Sport, ETH Zurich, Wolfgang-Pauli-Str. 27 8093 Zurich, Switzerland. ${ }^{5}$ Centre for Evidence Based Physiotherapy, Maastricht University, PO Box 6166200 MD Maastricht, the Netherlands.

Received: 14 April 2014 Accepted: 18 August 2014

Published: 22 August 2014

\section{References}

1. Koivusalo M, Mackintosh M: The World Health Report 2007. A Safer Future: Global Public Health Security in the 21st Century, Development and Change 2008, Volume 39. Geneva: World Health Organization; 2007:1163-1169.

2. Go AS, Mozaffarian D, Roger VL, Benjamin EJ, Berry JD, Borden WB, Bravata DM, Dai S, Ford ES, Fox CS, Franco S, Fullerton HJ, Gillespie C, Hailpern SM, Heit JA, Howard VJ, Huffman MD, Kissela BM, Kittner SJ, Lackland DT, Lichtman JH, Lisabeth LD, Magid D, Marcus GM, Marelli A, Matchar DB, McGuire DK, Mohler ER, Moy CS, Mussolino ME, et al: Executive summary: heart disease and stroke statistics-2013 update: a report from the American Heart Association. Circulation 2013, 127(1):143-152.

3. Truelsen T, Piechowski-Jozwiak B, Bonita R, Mathers C, Bogousslavsky J, Boysen G: Stroke incidence and prevalence in Europe: a review of available data. Eur J Neurol 2006, 13(6):581-598.

4. Go AS, Mozaffarian D, Roger VL, Benjamin EJ, Berry JD, Borden WB, Bravata DM, Dai S, Ford ES, Fox CS, Franco S, Fullerton HJ, Gillespie C, Hailpern SM, Heit JA, Howard VJ, Huffman MD, Kissela BM, Kittner SJ, Lackland DT, Lichtman JH, Lisabeth LD, Magid D, Marcus GM, Marelli A, Matchar DB, McGuire DK, Mohler ER, Moy CS, Mussolino ME, et al: Heart disease and stroke statistics-2013 update: a report from the American Heart Association. Circulation 2013, 127(1):e6-e245.

5. WHO: International Classification of Functioning, Disability and Health Geneva, Switzerland: World Health Organization; 2001.

6. Caspersen CJ, Powell KE, Christenson GM: Physical activity, exercise, and physical fitness: definitions and distinctions for health-related research. Public Health Reports (Washington, DC: 1974) 1985, 100(2):126-131.

7. Resistance Training Guidelines for Stroke. [http://www.ncpad.org/94/706/ Resistance Training for Persons with Physical Disabilities] 
8. Ramas J, Courbon A, Roche F, Bethoux F, Calmels P: Effect of training programs and exercise in adult stroke patients: literature review. Ann Readapt Med Phys 2007, 50(6):438-444. 430-437.

9. Ivey FM, Hafer-Macko CE, Macko RF: Exercise training for cardiometabolic adaptation after stroke. J Mol Signal 2008, 28(1):2-11.

10. Stoller $\mathrm{O}$, de Bruin ED, Knols RH, Hunt KJ: Effects of cardiovascular exercise early after stroke: systematic review and meta-analysis. BMC Neurol 2012, 12(1):45

11. Pang MY, Eng JJ, Dawson AS, Gylfadottir S: The use of aerobic exercise training in improving aerobic capacity in individuals with stroke: a metaanalysis. Clin Rehabil 2006, 20(2):97-111

12. Veerbeek JM, Koolstra M, Ket JC, van Wegen EE, Kwakkel G: Effects of augmented exercise therapy on outcome of gait and gait-related activities in the first 6 months after stroke: a meta-analysis. Stroke 2011, 42(11):3311-3315.

13. van de Port IG, Wood-Dauphinee S, Lindeman E, Kwakkel G: Effects of exercise training programs on walking competency after stroke: a systematic review. Am J Phys Med Rehabil 2007, 86(11):935-951.

14. Morris SL, Dodd KJ, Morris ME: Outcomes of progressive resistance strength training following stroke: a systematic review. Clin Rehabil 2004 18(1):27-39

15. Harris JE, Eng JJ: Strength training improves upper-limb function in individuals with stroke: A meta-analysis. Stroke 2010, 41(1):136-140.

16. Saunders DH, Sanderson M, Brazzelli M, Greig CA, Mead GE: Physical fitness training for stroke patients. Cochrane Database Syst Rev 2013, 10:CD003316.

17. Smith AC, Saunders DH, Mead G: Cardiorespiratory fitness after stroke: a systematic review. Int J Stroke 2012, 7(6):499-510.

18. Campbell KL, Neil SE, Winters-Stone KM: Review of exercise studies in breast cancer survivors: attention to principles of exercise training. $\mathrm{Br} J$ Sports Med 2012, 46(13):909-916.

19. Winters-Stone KM, Neil SE, Campbell KL: Attention to principles of exercise training: a review of exercise studies for survivors of cancers other than breast. Br J Sports Med 2014, 1(12):987-995.

20. Hoffman J (Ed): Physiological Aspects of Sport Training and Performance. Champaign, Illinois: Human Kinetics; 2002.

21. Reimer DJ: Physical Fitness Training. In Field Manual No 21-20, Volume 2. Edited by US-Army, vol 2. Washington DC: Headquarters Department of the Army; 1998:241.

22. Moher D, Hopewell S, Schulz KF, Montori V, Gøtzsche PC, Devereaux PJ, Elbourne D, Egger M, Altman DG: CONSORT 2010 Explanation and Elaboration: updated guidelines for reporting parallel group randomised trials. J Clin Epidemiol 2010, 2010(63):e1-e37.

23. Schulz K, Altman D, Moher D, the CONSORT Group: CONSORT 2010 Statement: updated guidelines for reporting parallel group randomised trials. BMC Med 2010, 8(1):18

24. World Health Organization, health topics: chronic diseases. [http://www. who.int/topics/chronic diseases/en/]

25. Higgins JP, Altman DG, Gøtzsche PC, Jüni P, Moher D, Oxman AD, Savović J, Schulz KF: The Chochrane Collaboration's tool for assessing risk of bias in randomised trials. Br Med J 2011, 343:1-9.

26. Landis JR, Koch GG: The measurement of observer agreement for categorical data. Biometrics 1977, 33(1):159-174.

27. Liberati A, Altman DG, Tetzlaff J, Mulrow C, Gotzsche PC, loannidis JP, Clarke M, Devereaux PJ, Kleijnen J, Moher D: The PRISMA statement for reporting systematic reviews and meta-analyses of studies that evaluate health care interventions: explanation and elaboration. J Clin Epidemiol 2009, 62(10):e1-e34

28. Moher D, Liberati A, Tetzlaff J, Altman DG: Preferred reporting items for systematic reviews and meta-analyses: the PRISMA statement. J Clin Epidemiol 2009, 62(10):1006-1012

29. Barbeau H, Visintin M: Optimal outcomes obtained with body-weight support combined with treadmill training in stroke subjects. Arch Phys Med Rehabil 2003, 84(10):1458-1465

30. Kosak MC, Reding MJ: Comparison of partial body weight-supported treadmill gait training versus aggressive bracing assisted walking post stroke. Neurorehabil Neural Repair 2000, 14(1):13-19.

31. Visintin M, Barbeau $H$, Korner-Bitensky N, Mayo NE: A new approach to retrain gait in stroke patients through body weight support and treadmill stimulation. Stroke 1998, 29(6):1122-1128.

32. Globas C, Becker C, Cerny J, Lam JM, Lindemann U, Forrester LW, Macko RF, Luft AR: Chronic stroke survivors benefit from high-intensity aerobic treadmill exercise: a randomized control trial. Neurorehabilitation and Neural Repair 2012, 26(1):85-95.

33. Moore JL, Roth EJ, Killian C, Hornby TG: Locomotor training improves daily stepping activity and gait efficiency in individuals poststroke who have reached a "plateau" in recovery. Stroke 2010, 41(1):129-135.

34. Quaney BM, Boyd LA, McDowd JM, Zahner LH, He J, Mayo MS, Macko RF: Aerobic exercise improves cognition and motor function poststroke. Neurorehabilitation and Neural Repair 2009, 23(9):879-885.

35. Lennon O, Carey A, Gaffney N, Stephenson J, Blake C: A pilot randomized controlled trial to evaluate the benefit of the cardiac rehabilitation paradigm for the non-acute ischaemic stroke population. Clin Rehabil 2008, 22(2):125-133.

36. Luft AR, Macko RF, Forrester LW, Villagra F, Ivey F, Sorkin JD, Whitall J, McCombe-Waller S, Katzel L, Goldberg AP, Hanley DF: Treadmill exercise activates subcortical neural networks and improves walking after stroke: a randomized controlled trial. Stroke 2008, 39(12):3341-3350.

37. Macko RF, Ivey FM, Forrester LW, Hanley D, Sorkin JD, Katzel LI, Silver KH, Goldberg AP: Treadmill exercise rehabilitation improves ambulatory function and cardiovascular fitness in patients with chronic stroke: a randomized, controlled trial. Stroke 2005, 36(10):2206-2211.

38. Peurala SH, Tarkka IM, Pitkanen K, Sivenius J: The effectiveness of body weight-supported gait training and floor walking in patients with chronic stroke. Arch Phys Med Rehabil 2005, 86(8):1557-1564.

39. Potempa K, Lopez M, Braun LT, Szidon JP, Fogg L, Tincknell T: Physiological outcomes of aerobic exercise training in hemiparetic stroke patients. Stroke 1995, 26(1):101-105

40. Bang D-H, Shin W-S, Kim S-Y, Choi J-D: The effects of action observational training on walking ability in chronic stroke patients: A double-blind randomized controlled trial. Clin Rehabil 2013, 27(12):1118-1125.

41. Carda S, Invernizzi M, Baricich A, Cognolato G, Cisari C: Does altering inclination alter effectiveness of treadmill training for gait impairment after stroke? A randomized controlled trial. Clin Rehabil 2013, 27(10):932-938.

42. Dean CM, Rissel C, Sherrington C, Sharkey M, Cumming RG, Lord SR, Barker RN, Kirkham C, O'Rourke S: Exercise to enhance mobility and prevent falls after stroke: The community stroke club randomized trial. Neurorehabil Neural Repair 2012, 26(9):1046-1057.

43. Jin H, Jiang Y, Wei Q, Chen L, Ma G: Effects of aerobic cycling training on cardiovascular fitness and heart rate recovery in patients with chronic stroke. NeuroRehabilitation 2013, 32(2):327-335.

44. Jin $H$, Jiang $Y$, Wei $Q$, Wang $B$, Ma G: Intensive aerobic cycling training with lower limb weights in Chinese patients with chronic stroke: discordance between improved cardiovascular fitness and walking ability. Disabil Rehabil 2012, 34(19):1665-1671.

45. Mayo NE, MacKay-Lyons MJ, Scott SC, Moriello C, Brophy J: A randomized trial of two home-based exercise programmes to improve functional walking post-stroke. Clin Rehabil 2013, 27(7):659-671.

46. Tang A, Eng JJ, Krassioukov AV, Madden KM, Mohammadi A, Tsang MYC, Tsang TSM: Exercise-induced changes in cardiovascular function after stroke: a randomized controlled trial. Int J Stroke 2013, doi:10.1111/ijs.12156.

47. Flansbjer UB, Miller M, Downham D, Lexell J: Progressive resistance training after stroke: effects on muscle strength, muscle tone, gait performance and perceived participation. J Rehabil Med 2008, 40(1):42-48

48. Yang YR, Wang RY, Lin KH, Chu MY, Chan RC: Task-oriented progressive resistance strength training improves muscle strength and functional performance in individuals with stroke. Clin Rehabil 2006, 20(10):860-870.

49. Ouellette MM, LeBrasseur NK, Bean JF, Phillips E, Stein J, Frontera WR, Fielding RA: High-intensity resistance training improves muscle strength, self-reported function, and disability in long-term stroke survivors. Stroke 2004, 35(6):1404-1409.

50. Kim CM, Eng JJ, Maclntyre DL, Dawson AS: Effects of isokinetic strength training on walking in persons with stroke: a double-blind controlled pilot study. J Stroke Cerebrovasc Dis 2001, 10(6):265-273.

51. Dean CM, Richards CL, Malouin F: Task-related circuit training improves performance of locomotor tasks in chronic stroke: a randomized, controlled pilot trial. Arch Phys Med Rehabil 2000, 81(4):409-417.

52. Clark DJ, Patten C: Eccentric versus concentric resistance training to enhance neuromuscular activation and walking speed following stroke. Neurorehabil Neural Repair 2013, 27(4):335-344. 
53. Lee NK, Kwon JW, Son SM, Kang KW, Kim K, Hyun-Nam S: The effects of closed and open kinetic chain exercises on lower limb muscle activity and balance in stroke survivors. NeuroRehabilitation 2013, 33(1):177-183.

54. Waldman G, Yang C-Y, Ren Y, Liu L, Guo X, Harvey RL, Roth EJ, Zhang L-Q: Effects of robot-guided passive stretching and active movement training of ankle and mobility impairments in stroke. NeuroRehabilitation 2013, 32(3):625-634

55. Duncan P, Studenski S, Richards L, Gollub S, Lai SM, Reker D, Perera S, Yates J, Koch V, Rigler S, Johnson D: Randomized clinical trial of therapeutic exercise in subacute stroke. Stroke 2003, 34(9):2173-2180.

56. Duncan P, Richards L, Wallace D, Stoker-Yates J, Pohl P, Luchies C, Ogle A, Studenski S: A randomized, controlled pilot study of a home-based exercise program for individuals with mild and moderate stroke. Stroke 1998, 29(10):2055-2060.

57. Salbach NM, Mayo NE, Wood-Dauphinee S, Hanley JA, Richards CL, Cote R: A task-orientated intervention enhances walking distance and speed in the first year post stroke: a randomized controlled trial. Clin Rehabil 2004, 18(5):509-519.

58. Lee M, Kilbreath SL, Singh MF, Zeman B, Davis GM: Effect of progressive resistance training on muscle performance after chronic stroke. Med Sci Sports Exerc 2010, 42(1):23-34.

59. Lee M-J, Kilbreath SL, Singh MF, Zeman B, Lord SR, Raymond J, Davis GM: Comparison of effect of aerobic cycle training and progressive resistance training on walking ability after stroke: a randomized sham exercisecontrolled study. J Am Geriatr Soc 2008, 56(6):976-985.

60. Pang MYC, Eng JJ: Determinants of improvement in walking capacity among individuals with chronic stroke following a multi-dimensional exercise program. J Rehabil Med 2008, 40(4):284-290.

61. Mead GE, Greig CA, Cunningham I, Lewis SJ, Dinan S, Saunders DH, Fitzsimons C, Young A: Stroke: A randomized trial of exercise or relaxation. J Am Geriatr Soc 2007, 55(6):892-899.

62. Olney SJ, Nymark J, Brouwer B, Culham E, Day A, Heard J, Henderson M, Parvataneni $K$ : A randomized controlled trial of supervised versus unsupervised exercise programs for ambulatory stroke survivors. Stroke 2006, 37(2):476-481.

63. Pang MY, Eng JJ, Dawson AS, McKay HA, Harris JE: A community-based fitness and mobility exercise program for older adults with chronic stroke: a randomized, controlled trial. J Am Geriatr Soc 2005, 53(10):1667-1674.

64. Carr M, Jones J: Physiological effects of exercise on stroke survivors. Top Stroke Rehabil 2003, 9(4):57-64

65. Teixeira-Salmela LF, Olney SJ, Nadeau S, Brouwer B: Muscle strengthening and physical conditioning to reduce impairment and disability in chronic stroke survivors. Arch Phys Med Rehabil 1999, 80(10):1211-1218.

66. Kwakkel G: Impact of intensity of practice after stroke: issues for consideration. Disabil Rehabil 2006, 28(13-14):823-830.

67. Borg G: Borg's Rating of Perceived Exertion and Pain Scales. Champaign, IL: Human Kinetics; 1998.

68. Lohse KR, Lang CE, Boyd LA: Is more better? Using metadata to explore dose-response relationships in stroke rehabilitation. Stroke 2014 45(7):2053-2058

69. Kwakkel G, van Peppen R, Wagenaar RC, Wood Dauphinee S, Richards C, Ashburn A, Miller K, Lincoln N, Partridge C, Wellwood I, Langhorne P: Effects of augmented exercise therapy time after stroke: a meta-analysis. Stroke 2004, 35(11):2529-2539.

70. Duncan F, Kutlubaev MA, Dennis MS, Greig C, Mead GE: Fatigue after stroke: a systematic review of associations with impaired physical fitness. Int J Stroke 2012, 7(2):157-162

71. Young CA, Mills RJ, Gibbons C, Thornton EW: Poststroke fatigue: the patient perspective. Top Stroke Rehabil 2013, 20(6):478-484

72. Nicholson S, Sniehotta FF, van Wijck F, Greig CA, Johnston M, McMurdo ME, Dennis M, Mead GE: A systematic review of perceived barriers and motivators to physical activity after stroke. Int J Stroke 2013, 8(5):357-364.

73. Roth EJ, Heinemann AW, Lovell LL, Harvey RL, McGuire JR, Diaz S: Impairment and disability: their relation during stroke rehabilitation. Arch Phys Med Rehabil 1998, 79:329-335.

74. Tilson JK, Wu SS, Cen SY, Feng Q, Rose DR, Behrman AL, Azen SP, Duncan PW: Characterizing and identifying risk for falls in the LEAPS study: a randomized clinical trial of interventions to improve walking poststroke. Stroke 2012, 43(2):446-452

75. Billinger SA, Arena R, Bernhardt J, Eng JJ, Franklin BA, Johnson CM, MacKay-Lyons M, Macko RF, Mead GE, Roth EJ, Shaughnessy M, Tang A, American Heart
Association Stroke Council, Council on Cardiovascular and Stroke Nursing, Council on Lifestyle and Cardiometabolic Health, Council on Epidemiology and Prevention, and Council on Clinical Cardiology: Physical Activity and Exercise Recommendations for Stroke Survivors: A Statement for Healthcare Professionals from the American Heart Association/ American Stroke Association. Stroke 2014, 45(8):2532-2553.

76. Wood L, Egger M, Gluud LL, Schulz KF, Jüni P, Altman DG, Gluud C, Martin RM, Wood AJG, Sterne JAC: Empirical evidence of bias in treatment effect estimates in controlled trials with different interventions and outcomes: meta-epidemiological study. BMJ 2008, 336(7644):601-605.

77. Clark L, Schmidt U, Tharmanathan P, Adamson J, Hewitt C, Torgerson D: Poor reporting quality of key Randomization and Allocation Concealment details is still prevalent among published RCTs in 2011: a review. J Eval Clin Pract 2013, 19(4):703-707.

78. Herbison P, Hay-Smith J, Gillespie WJ: Different methods of allocation to groups in randomized trials are associated with different levels of bias. A meta-epidemiological study. J Clin Epidemiol 2011, 64(10):1070-1075.

79. Kluding PM, Tseng BY, Billinger SA: Exercise and executive function in individuals with chronic stroke: a pilot study. J Neurol Phys Ther 2011, 35(1):11-17.

80. Rand D, Eng JJ, Liu-Ambrose T, Tawashy AE: Feasibility of a 6-month exercise and recreation program to improve executive functioning and memory in individuals with chronic stroke. Neurorehabil Neural Repair 2010, 24(8):722-729.

81. Mang CS, Campbell KL, Ross CJ, Boyd LA: Promoting neuroplasticity for motor rehabilitation after stroke: considering the effects of aerobic exercise and genetic variation on brain-derived neurotrophic factor. Phys Ther 2013, 93(12):1707-1716.

82. Takatori K, Matsumoto D, Okada Y, Nakamura J, Shomoto K: Effect of intensive rehabilitation on physical function and arterial function in community-dwelling chronic stroke survivors. Top Stroke Rehabil 2012, 19(5):377-383.

83. Rimmer $\mathrm{JH}$, Rauworth $\mathrm{AE}$, Wang EC, Nicola $\mathrm{TL}$, Hill B: A preliminary study to examine the effects of aerobic and therapeutic (nonaerobic) exercise on cardiorespiratory fitness and coronary risk reduction in stroke survivors. Arch Phys Med Rehabil 2009, 90(3):407-412.

84. Ivey FM, Ryan AS, Hafer-Macko CE, Goldberg AP, Macko RF: Treadmill aerobic training improves glucose tolerance and indices of insulin sensitivity in disabled stroke survivors: a preliminary report. Stroke 2007, 38(10):2752-2758.

85. Tseng BY, Kluding P: The relationship between fatigue, aerobic fitness, and motor control in people with chronic stroke: a pilot study. J Geriatr Phys Ther 2009, 32(3):97-102.

86. Wu S, Barugh A, Macleod M, Mead G: Psychological associations of poststroke fatigue: a systematic review and meta-analysis. Stroke 2014, 45(6):1778-1783.

87. English C, Manns PJ, Tucak C, Bernhardt J: Physical activity and sedentary behaviors in people with stroke living in the community: a systematic review. Phys Ther 2014, 94(2):185-196.

88. Rosewilliam S, Roskell CA, Pandyan AD: A systematic review and synthesis of the quantitative and qualitative evidence behind patient-centred goal setting in stroke rehabilitation. Clin Rehabil 2011, 25(6):501-514.

89. Gordon NF, Gulanick M, Costa F, Fletcher G, Franklin BA, Roth EJ, Shephard T: Physical activity and exercise recommendations for stroke survivors: an American Heart Association scientific statement from the Council on Clinical Cardiology, Subcommittee on Exercise, Cardiac Rehabilitation, and Prevention; the Council on Cardiovascular Nursing; the Council on Nutrition, Physical Activity, and Metabolism; and the Stroke Council. Circulation 2004, 109(16):2031-2041.

90. Brethour MK, Nystrom KV, Broughton S, Kiernan TE, Perez A, Handler D, Swatzell V, Yang JJ, Starr M, Seagraves KB, Cudlip F, Biby S, Tocco S, Owens $P$, Alexandrov AW: Controversies in acute stroke treatment. AACN Adv Crit Care 2012, 23(2):158-172. quiz 173-154.

\section{doi:10.1186/s12883-014-0167-2}

Cite this article as: Ammann et al:: Application of principles of exercise training in sub-acute and chronic stroke survivors: a systematic review. BMC Neurology 2014 14:167. 